\title{
UMA EDUCAÇÃO POR VIR: INFÂNCIA E POTÊNCIA
}

\author{
BetinA Hillesheim*
}

\begin{abstract}
RESUMO: Este artigo propõe discutir, a partir do conto $O$ rio das quatro luzes, de Mia Couto, as conexões entre infância e educação. Para isso, utilizando-se de dois personagens conceituais, o Pai e o Avô, colocam-se algumas questões relativas ao tempo e seu enlaçamento com a infância. A seguir, foca-se a educação e sua relação com a infância, buscando novas composições que façam pensar a educação através de práticas que não busquem somente a decifração dos códigos, mas, a partir da criação de agenciamentos, provoquem o pensamento, dizendo sim à vida e multiplicando as formas de existência.
\end{abstract}

Palavras-chave: Infância. Tempo. Educação.

\section{AN EDUCATION YET TO COME: CHILDHOOD AND POTENCY}

ABSTRACT: This paper discusses the connections between childhood and education, having the short story called $O$ rio das quatro luzes, by Mia Couto, as its starting point. By considering two conceptual characters, the Father and the Grandfather, some issues related to time and its link to childhood have been presented. Education and its relationship with childhood have also been focused, in search of new compositions that lead us to think about Education through practices that don't merely seek code deciphering, but also instigate thinking, based on the creation of agencies, by not only saying 'yes' to life but also by multiplying the forms of existence.

Key words: Childhood. Time. Education.

\section{UNE ÉDUCATION À VENIR: ENFANCE ET POUVOIR}

RÉSUMÉ: Cet article propose de discuter, à partir du conte $O$ rio das quatro luzes, de Mia Couto, les rapports entre l'enfance et l'enseignement. Pour cela, en s'utilisant de deux personnages conceptuels, le Père et le Grandpère, se posent quelques questions relatives au temps et à sa liaison avec l'enfance. Ensuite, on évidencie l'enseignement et sa relation avec l'enfance, en cherchant de nouvelles compositions pour faire penser à l'enseignement

Doutora em Psicologia e professora do Departamento de Psicologia e do Mestrado em Educação da Universidade de Santa Cruz do Sul (Unisc). E-mail: betinah@unisc.br 
à travers les pratiques qui ne cherchent pas seulement le déchiffrement des codes, mais qu'à partir de la création d'agencements ils provoquent la pensée, en disant oui à la vie et en multipliant les formes d'existence.

Mots-clés: Enfance. Temps. Éducation.

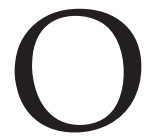

conto $\mathrm{O}$ rio das quatro luzes, de Mia Couto, inicia com um menino que declara a sua mãe, durante a passagem de um cortejo fúnebre: mãe, eu também quero ir em caixa daquelas. Estremece a mãe e, à noite, o pai busca conversar sobre o acontecido. E, ante a preocupação paterna, o menino anuncia: eu não quero mais ser criança. [...] Quero envelhecer rápido, pai. Ficar mais velho que o senhor. E segue em suas reflexões:

Que valia ser criança se lhe faltava a infância? Este mundo não estava para meninices. Porque nos fazem com esta idade, tão pequenos, se a vida aparece sempre adiada para outras idades, outras vidas? Deviam-nos fazer já graúdos, ensinados a sonhar com conta medida. Mesmo o pai passava a vida louvando a sua infância, seu tempo de maravilhas. Se foi para lhe roubar a fonte desse tempo, porque razão o deixaram beber dessa água? (COUTO, 2009, p. 112)

Por que escolho este fragmento literário para pensar as conexões entre infância e educação? Entendo que há muitos ingressos possíveis, mas a proposta que faço é dialogar com a Educação a partir de dois personagens conceituais, inspirados no conto de Mia Couto: o Pai e o Avô. A construção destes personagens não visa prescrever formas de educar, estabelecendo juízos de valor ou classificações; nem mesmo pretende afirmar que estes personagens sejam independentes um do outro, opostos ou dicotômicos; mas, através destes, fazer emergir outro personagem - o Educador. Se estes personagens são viáveis, não posso afirmá-lo de antemão, mas, mediante este exercício, busco engendrar alguma imagem de pensamento que produza movimento no campo da Educação, de modo a inverter a corrente do rio e deixar que a infância nos guie, curvando o tempo e aproximando as idades: filhos, pais e avôs que se encontram na invenção de territórios educativos e de outras relações possíveis entre quem ensina e quem aprende.

Assinalo que, conforme Deleuze e Guattari (1997, p. 86), “o personagem conceitual nada tem a ver com uma personificação abstrata, um símbolo ou uma alegoria, pois ele vive, ele insiste". Um personagem conceitual é um agente de enunciação, que, ao ser pensado, provoca movimento. Ao nomear um personagem conceitual como Pai ou Avô, por exemplo, o pai ou o avô não perdem sua existência concreta, mas assumem uma nova existência, transformando-se em "condições interiores do pensamento para seu exercício real" (p. 92), traçando planos e criando conceitos. Personagens conceituais são potências de conceitos. 
Dessa maneira, busca-se afastar das figuras do professor que Chesterton, no início do século XX, denominou como educador-instrutor - aquele que coloca na criança aquilo que pretende que ela aprenda - e educador-sacador - aquele que faz sair da criança o que quer, visto que, como ele aponta, quaisquer dessas atitudes, empurrar ou puxar, são idênticas no que se refere à violência empregada (NÓVOA, 2003). Ambas as figuras parecem encontrar-se no camelo ${ }^{1}$ descrito por Nietzsche (2008) em Assim falou Zaratustra: um espírito que carrega o pesado fardo do dever, renunciando à liberdade em respeito à tradição; um espírito que desfruta da carga que carrega, pois entende que, quanto mais pesada, mais sua força é colocada à prova. O camelo, assim como o educador-instrutor e o educador-sacador, é o espírito do "tu deves". Como pensar em outra figura para o educador?

Falar em Pai e Avô remete ao tempo. Desse modo, em um primeiro momento, utilizo o conto de Mia Couto para pensar algumas questões sobre o tempo e seu enlaçamento com a infância, a partir do delineamento destes personagens conceituais. A seguir, trago o foco para a educação e sua relação com a infância, buscando novas composições que produzam solavancos (ou pelo menos alguns abalos) nas nossas certezas. Afinal, "os personagens conceituais têm este papel, manifestar os territórios, desterritorializações e reterritorializações absolutas do pensamento" (DELEUZE; GUATTARI, 1997, p. 92).

\section{Tempo e infância}

O menino do conto nos surpreende de imediato: uma criança que deseja a morte. E seu argumento é forte: por que desejar viver a infância se ela nos é roubada pela perspectiva de tornar-se adulto? Uma vida adiada para outras idades; qual o sentido da mesma? A infância voltada para o futuro e o adulto lamentando a infância perdida: a morte surge como uma oportunidade. Afinal, "ter alguém assim que chore por nós, quanto vale uma tristeza dessas?" (COUTO, 2009, p. 111). Diante da insistência do menino, o pai o ameaça e, por fim, desiste. O Avô, porém, propõe um negócio: falaria com Deus e proporia uma troca nas leis do tempo, requerendo que o menino morresse em seu lugar.

Uma troca nas leis do tempo? Agamben (2005) afirma que a cultura pressupõe determinada experiência do tempo, sendo que uma nova cultura exige a transformação desta experiência. Portanto, uma autêntica revolução significa não somente mudar o mundo, mas, sobretudo, mudar o tempo. Por conseguinte, para pensar sobre esta proposta do Avô, trago as reflexões deste autor sobre diferentes concepções de tempo e seus efeitos sobre a experiência.

A concepção greco-romano do tempo é circular e contínua, o que se desdobra nas seguintes consequências: 1) sendo circular, o tempo não possui direção, 
retornando, incessantemente, sobre si mesmo; 2) na medida em que se define como um número de movimentos divididos, a partir da ideia de instante, pelo antes e pelo depois, o tempo se constitui como um continuum pontual, infinito e quantificado. É nesta representação do tempo como instantes pontuais em fuga que se fundamenta o sentimento de incapacidade do homem ocidental sobre o domínio do tempo, assim como sua luta em ganhar tempo ou fazê-lo passar. Nesse sentido, Agamben (op. cit., p. 114) afirma que "uma cultura com semelhante representação do tempo não poderia ter uma experiência genuína de historicidade", pois entende o tempo como algo que deve ser combatido, tendo em vista seu caráter destrutivo.

Diferentemente do tempo circular e sem direção da antiguidade grega, para a experiência cristã o tempo é uma linha reta, que se estende da criação ao fim, sendo que cada evento acontece somente uma vez. O tempo é dissociado do curso natural dos astros, tornando-se um fenômeno humano e interior. Contudo, mesmo interiorizado, o tempo segue sendo compreendido como uma sucessão contínua de instantes pontuais: não se trata da abolição do tempo contínuo e quantificado, mas de sua transferência do movimento dos astros para o interior humano.

O advento do capitalismo traz uma nova forma de concepção de tempo, visto que a experiência do trabalho nas fábricas inscreve o movimento retilíneo uniforme como prioritário sobre o movimento circular. A vida nos centros urbanos também é caracterizada pela experiência de um tempo morto e subtraído à experiência, reforçando a ideia de que o único tempo humano é o instante pontual em fuga. Assim, a representação do tempo da Idade Moderna é a de um tempo homogêneo, retilíneo e vazio. A história é vista como linear e evolutiva, sendo que o sentido apenas pode ser dado a partir da ideia de um processo cronologicamente orientado.

A partir destas reflexões, Agamben (2005, p. 122) conclui que "quer seja pensado como círculo, quer como linha, o caráter que domina toda concepção ocidental do tempo é a pontualidade". Para pensar o tempo de outra maneira é necessário, portanto, realizar uma crítica do instante, o que ele vai buscar em elementos dispersos nas sombras da tradição cultural ocidental, como a Gnose e o Pórtico. A primeira se refere a uma religião malograda no Ocidente, que se contrapõe radicalmente às experiências de tempo na tradição grega e cristã. Para a Gnose, o tempo corresponde a uma linha partida, a qual é marcada por uma absoluta estrangeiridade. Trata-se de um tempo incoerente e não homogêneo, que não considera a redenção no sentido cristão, isto é, como algo a ser alcançado, mas como algo que já aconteceu desde sempre e do qual o homem, em um súbito ato de consciência, se apossa. Já o Pórtico, a doutrina dos estoicos, recusa tanto a imagem da eternidade quanto o instante matemático, criticando o adiamento infinito implicado nesta compreensão de tempo. Diante disso, os estoicos concebem o tempo como algo que surge da ação e decisão humanas, tendo como modelo o cairós, o qual concentra vários tempos em si. 
Percebe-se, assim, uma crítica ao tempo contínuo e quantificado. Nesta perspectiva, Walter Benjamin propõe um tempo-agora, substituindo o presente nulificado por um presente que se mantém imóvel, constituindo-se como um estado da história, "cujo evento fundamental está sempre em curso e cuja meta não se encontra distante no futuro, mas já sempre presente" (AGAMBEN, op. cit., p. 124).

Costa (2000), discutindo o pensamento de Lévinas sobre os temas da alteridade e da temporalidade, sublinha que, para este autor, o tempo não é uma mera sucessão de instantes pontuais, percorridos por um eu que vai de um instante a outro, sempre se reencontrando consigo mesmo, visto que se trata de um mesmo tempo, um tempo sincrônico. Nessa visão, o tempo garante a continuidade na existência do sujeito, a qual se dá sem intervalos. Para Lévinas, o tempo é diacrônico, constituindo-se como uma um modo diferente de si: entre o instante presente e o instante seguinte, há um intervalo do nada, o qual é produzido pelo adormecimento da consciência. Assim, não se trata de um tempo de continuidade, mas de um novo início que ocorre com o despertar da consciência; o tempo é lugar de nascimento, tanto de estranhamento quanto de um lugar diferente do si mesmo. Portanto, alteridade e temporalidade estão enlaçadas, sendo o tempo uma forma de saída de si.

O menino reclama da infância esmagada no tempo: embora a mãe pontue que a vida é uma prenda, ele não lhe vê graça. A morte lhe é mais sedutora: quebra de toda a cronologia, libertação de si. Para estar morto, como lhe diz o Avô, é necessário estar nu como um búzio, ser leve como a lua, ficar escuro na escuridão... É preciso, portanto, sair de si ou, como nos aponta Lévinas (apud COSTA, 2000), abrir-se para um além de e um modo diferente de. Entretanto, à morte, o Avô contrapõe uma alternativa: enquanto não fosse tudo acertado com Deus, a troca entre sua morte e a do menino, que este fosse "meninando, distraído nos brincados" (COUTO, 2009, p. 113).

À fala do Pai - não diga isto, Deus lhe castiga -, o Avô traça outros caminhos: o que ele lembra são os lugares secretos de sua infância, o mais antigo de sua existência. Em sua companhia, "o moço se criançava, convertido em menino" (idem, ibid.). E o Avô ensina aos adultos que criancice não se desempenha sozinha, é necessário que esses se dispam da idade e desobedeçam ao tempo: o milagre que um filho oferece é a possibilidade de nascermos para outras vidas.

Côrrea (2009) retoma a pergunta nietzschiana: como construir um tempo que virá? E, para respondê-la, apoiado em Nietzsche, traz a ideia do intempestivo: um tempo que virá foge à linearidade, dispensando as noções de antes, durante e depois. Um tempo que virá está implicado na criação vertiginosa do novo e, portanto, não se reduz à memória ou ao instante. Enquanto, para o animal, o ser do tempo é o esquecimento, sendo que cada instante é esquecido no momento em que passa, o homem carrega o fardo do tempo e de seu passado. A memória excessivamente 
desenvolvida é danosa, pois enterra o próprio presente: a vida só vinga com o esquecimento. Mas Nietzsche, conforme lembra o autor, não sugere que a amnésia é a fórmula da felicidade, pois não é possível desfazer-se do passado: o homem oscila entre a memória e a vida, cabendo a ele ser forte para servir-se do passado em prol da vida, admitindo a prerrogativa daquilo que deve nascer. Só se pode desprender do passado quando há o desejo que este tenha sido precisamente como foi, dizendo-se: "outra vez! E mais outra!". Nesta perspectiva, o eterno retorno adquire uma dimensão trágica, visto que se está destinado a desejar que tudo ocorra novamente. Só a partir da aceitação do peso do próprio passado é possível o novo. Trata-se, assim, de amor ao devir dos acontecimentos, considerando-se que nunca é o Mesmo que retorna, mas este só volta para trazer o que difere. "A repetição é a forma do devir. Portanto, o que devém só pode ser diferente" (CORRÊA, 2009, p. 371). É somente neste tempo a-histórico que ocorre a criação.

Deleuze e Guattari (1997, p. 223) perguntam: "como tornar um momento do mundo durável ou fazê-lo existir por si?". E se valem de uma frase utilizada por Virgínia Woolf: saturar cada átomo. Para os autores, os artistas e os filósofos, muitas vezes, por verem na vida algo grande demais, trazem consigo a marca da morte. Assim, diz o menino: mãe, eu também quero ir em caixa daquelas. Assim, diz o Avô: estar morto implica ficar nu, ser leve, tornar-se escuro... Assim, diz Virgínia Woolf: saturar cada átomo. Tornar os momentos duráveis, fazendo-os existir por si. O rio inverte a direção, o Avô entrega-se à morte e pede que avisem ao neto que mentira, pois nunca fizera pedido nenhum a Deus. Mas o recado não chega: "Longe, na residência do casal, o menino sentiu reverter-se o caudal do tempo. E os seus olhos se intemporaram em duas pedrinhas. No leito do rio se afundaram quatro luzências" (COUTO, 2009, p. 115).

O menino e o Avô se encontram em um entretempo: não há mais presente, passado, futuro ou instante. Agem, assim, em defesa de um tempo por vir. Confundem o Pai, tão imbuído dos códigos e das cronologias. Invertendo a direção do rio, embaralham os códigos: a morte é leveza, nudez, possibilidade de vida. Sua morte grita: “outra vez! De novo!". E a infância liberta-se do tempo, deixando de caminhar para o futuro e para o lamento do passado perdido: o menino, ao tornar-se criança, envelhece rápido. Avô e menino fundem-se, transformando-se em luzes no leito do rio.

\section{Imagens para a educação}

Por que problematizar nossa relação com o tempo pode contribuir para a educação? No âmbito deste artigo, apontam-se dois motivos para tal. Primeiro, porque pensar o tempo pressupõe pensar o espaço, visto que um não existe descolado da experiência do outro. Portanto, nossa relação com o tempo liga-se intimamente com 
a relação com espaço, sendo que a educação escolarizada moderna é marcada por um determinado modo de conceber o tempo e organizar o espaço, cuja naturalização encobre os poderes colocados em jogo na sua invenção. Segundo, porque colocar sob suspeita a maneira como esses elementos põem em funcionamento a educação escolarizada possibilita desmontarmos as engrenagens do que está posto, dizendo sim à vida e multiplicando as formas de existência. Trata-se aqui de um sim à moda de Zaratustra, ou seja, o sim da criança, que é dançarina, e não do camelo, cujo espírito é carregador. Desse modo, como afirma Godinho (2008, p. 1), "que pensar seja criar", mesmo que às vezes não seja certo que o consiga, mas se busque desprender da imitação, da representação, fazendo com que algo se passe ou se jogue, deixando o pensamento brotar de outro lugar.

Utiliza-se aqui, portanto, a infância como símbolo de afirmação, quebra da continuidade e do estabelecido (KOHAN, 2003). Este autor, discutindo os fragmentos de Heráclito, aponta que há dois usos distintos para o termo "criança": por um lado, a criança como oposta ao adulto; por outro, criança como algo que não tem oposto, mas que joga um jogo de oposições e que se refere ao próprio tempo da experiência. Assim, é relevante que, conforme Agamben (2005), em um dos fragmentos de Heráclito, uma das imagens do tempo - Aion, o tempo em seu caráter originário, a força vital que é percebida como temporal - figure como "uma criança que joga com os dados".

A criança joga. O menino e o Avô encontram-se em um tempo crianceiro. Porém, a educação é regida por outro tempo: um tempo linear, objetivo, contínuo. Um tempo que quantifica seus instantes, que se esforça em não deixá-los passar, que busca, ao máximo, aproveitá-los, pois não se pode perder tempo. Agora é aula de Geografia, depois estudar-se-á Matemática, meia hora de intervalo para lanchar e correr no pátio, todos voltam e se concentram em Português... Tempo medido para aprendizagens: até maio deve-se dominar tal conteúdo, em junho avalia-se novamente; se ainda não alcançou deve recuperá-lo em tantas horas (ou dias, ou semanas...), final do ano, avaliação final. Assim, transforma-se o menino, que, quanto mais rapidamente aprender e amadurecer, mais se aproximará do Pai, o modelo. Ao mesmo tempo em que se enaltece a infância, esta é uma condição que deve ser rapidamente superada, em nome dos ideais, das leis, da civilização. E o menino se encolhe, reduz-se, míngua sua infância, sorvendo os instantes que não podem ser perdidos no caminho da esperada maturidade. Melhor dizer: "mãe, eu também quero ir em caixa daquelas", pois o que lhe pedem é que deixe a infância para trás, ganhe tempo.

Entretanto, como lembra Godinho (2008), a criança sempre volta ao jogo, podendo interrompê-lo várias vezes ou jogar vários ao mesmo tempo, jogando, interrompendo-o e voltando quantas vezes quiser, retomando-o no ponto onde havia parado. Aos olhos do adulto, isto parece dispersão, mas, ao voltar, a criança volta 
não ao mesmo jogo, mas a um jogo diferente: a cada vez joga-se tudo o que há para jogar. Afirma-se assim como ser do devir, a partir do jogo que se joga segundo a lei do eterno retorno. Trata-se de um mundo que devém, "um mundo intenso em que tudo repousa sobre disparidades, diferenças de diferenças que se repercutem indefinidamente" (GODINHO, op. cit., p. 3). Jogar como potência afirmativa e, seguindo as indicações de Nietzsche, abandonar-se temporariamente à vida para nela fixar o olhar, dando as boas vindas ao acaso e gerando uma estrela dançarina com o caos que esta carrega consigo (DELEUZE, 1976).

Não se trata aqui de garantir espaços de trocas: "dê-me aqui, menino, sua atenção nestes dois períodos de História, que depois poderás jogar". Trata-se, assim, de roubo, pois como assinala Deleuze (2006), enquanto a troca é da ordem da generalidade, o roubo é o critério da repetição. Assim, enquanto a cabeça é o órgão das trocas, a repetição aloja-se no coração, sendo que, embora a repetição também se refira à cabeça, é precisamente porque é seu terror ou paradoxo. Godinho (2008, p. 6), ao comentar essa distinção realizada por Deleuze, pontua que "a troca nivela por baixo", sendo que se está falando de um plano no qual é impossível trocar (a alma, por exemplo). O roubo rasga, causa surpresa, restituindo a novidade. No jogo da criança, o roubo suspende as regras do que se entende, geralmente, por roubo. No jogo da criança, o roubo não se vincula à noção de posse, mas a trapaça (diferente do mundo adulto) causa riso. Cria-se assim algo que não pertence a ninguém, retornando sempre o que difere. Jogo do acaso, que, de um só lance, afirma o devir e o ser do devir, constituindo-se como afirmação do acaso, em uma combinação sempre vitoriosa. "Nenhum lance prevalece sobre outro, cada um exprime o todo do acaso. Na afirmação de todas as fórmulas, o que conta é que elas sejam sempre todas diferentes" (ibid., p. 14). Inventam-se, assim, as próprias regras.

Diante da questão do menino, enquanto o Pai traça os limites, o Avô improvisa, introduzindo o acaso. Improvisar, diz Gil (2008), é um exercício de alto risco. Como improvisar na educação, esta senhora sisuda, cheia de normas, cadernos de caligrafia, avaliações, silêncios, horários, corpos enfileirados e imóveis, olhos atentos, risos contidos? Como improvisar em um território encoberto pela sombra de Platão, onde o riso não convém? Afinal, como assinala Hanna Arendt (apud KOHAN, 2003), a necessidade de educação surge justamente da ruptura entre a irrupção do novo e o que já está dado, constituindo-se como uma reação à experiência do nascimento.

\section{Reflexões finais}

Na educação há uma série de verdades que sustentam suas práticas, como, por exemplo, a noção de desenvolvimento infantil e de uma suposta sequência lógica na aprendizagem. Ao utilizar o conto de Mia Couto, proponho fazer um exercício 
de buscar outras imagens possíveis para a educação, outras políticas do aprender, mediante a introdução do problema do tempo. Trata-se, assim, de desmantelar nossas certezas, investindo na criação de outros modos de educar e compreender a infância. Modos estes, como salientam Barros e Morschel (2012, p. 62), "pelos quais estamos sempre em vias de diferir" e que implicam, necessariamente, a imersão em um plano de experiência, a qual não é compreendida como algo já dado, mas é sempre emergência da mudança.

Ao entender a infância como experimentação, fluxos de intensidades, multiplicidades, mais do que uma questão cronológica, uma etapa de vida, esta passa a ser figura da descontinuidade, do possível, do porvir, uma relação intensiva com o tempo. Uma infância que, seguindo as indicações de Deleuze e Guattari (1997), age contra o tempo e sobre o tempo, em favor de um tempo por vir, sendo que o porvir não é o futuro, mas o infinito Agora, "não um instante, mas um devir" (p. 145) ou ainda o que é denominado por Foucault como Atual: não o que somos, "mas antes o que nos tornamos, o que estamos nos tornando", o Novo, o Interessante, nosso devir-outro.

Talvez, como colocam Deleuze e Guattari (2002), a questão não seja como escapar à palavra de ordem, mas escapar à sentença de morte que esta envolve, desenvolvendo a sua potencialidade revolucionária. Como transformar as composições de ordem presentes na educação em componentes de passagem? Como armar tensores na educação, extraindo gritos, clamores, timbres e intensidades? Como pensar a educação através de práticas que busquem criar agenciamentos, que não busquem somente a decifração dos códigos, mas que provoquem o pensamento, aventurando-se por caminhos impensados?

Uma educação que faça do devir uma afirmação, não buscando explicar ou interpretar, mas tão só experimentar. Uma educação que roube a infância, tal como o Avô que, afinal, não havia feito nenhuma troca com Deus (mesmo porque não se tratava de um objeto passível de troca) e, trapaceando junto com o menino, desobedece ao tempo cronológico e esquiva-se do corpo e do juízo. Uma educação do riso, da dança, dos folguedos. Enquanto isso, o menino distrai-se nos brincados.

\section{Nota}

1. Na passagem Três metamorfoses, Nietzsche traça as transformações do espírito a partir das formas do camelo, do leão e da criança.

\section{Referências}

AGAMBEN, G. Infância e história: destruição da experiência e origem da história. Belo Horizonte: UFMG, 2005. 
BARROS, M.E.B.; MORSCHEL, A. Conhecer. In: FONSECA, T.G.; NASCIMENTO, M.L.; MARASCHIN, C. (Org.). Pesquisar na diferença: um abecedário. Porto Alegre, Sulina, 2012. p. 61-64.

CORRÊA, M.D.C. Tríptico para um pensamento intempestivo: Nietzsche, Bergson e Deleuze. Prisma Jurídico, São Paulo, v. 8, n. 2, p. 363-382, jul./dez. 2009.

COSTA, M.L. Lévinas: uma introdução. Petrópolis: Vozes, 2000.

COUTO, M. O rio das Quatro Luzes. In: COUTO, M. O fio das missangas. São Paulo: Cia das Letras, 2009. p. 111-116.

DELEUZE, G. Nietzsche e a filosofia. Rio de Janeiro: Rio, 1976

DELEUZE, G. Diferença e repetição. 2. ed. Rio de Janeiro: Graal, 2006.

DELEUZE, G.; GUATTARI, F. O que é a filosofia? 2. ed. Rio de Janeiro: Editora 34, 1997. DELEUZE, G.; GUATTARI, F. Mil platôs: capitalismo e esquizofrenia. Rio de Janeiro: Editora 34, 2002. v. 2.

GIL, J. Ritornelo e imanência. In: LINS, D.; GIL, J. (Org.). Nietzsche/Deleuze jogo e música. Rio de Janeiro: Forense Universitária; Fortaleza: Fundação de Cultura, Esporte e Turismo, 2008. p. 125-141.

GODINHO, A. Eterno retorno e jogo ideal: o roubo ideal. In: LINS, D.; GIL, J. (Org.). Nietzsche/Deleuze jogo e música. Rio de Janeiro: Forense Universitária; Fortaleza: Fundação de Cultura, Esporte e Turismo, 2008. p. 1-18.

KOHAN, W. Infância: entre educação e filosofia. Belo Horizonte: Autêntica, 2003.

NIETZSCHE, F. Assim falava Zaratustra. 2. ed. Petrópolis: Vozes, 2008.

NÓVOA, A. Prefácio. In: Ó, J.R. O governo de si mesmo. Lisboa: Educa, 2003. p. xxiixxiv.

Recebido em 24 de outubro de 2012.

Aprovado em 13 de dezembro de 2012. 